\title{
Los pensamientos del indio que se educó dentro de las selvas colombianas
}

\author{
Manuel Quintín Lame
}

"Los pensamientos del indio que se educó dentro de las selvas colombianas", en Cristóbal Gnecco (editor), Los pensamientos del indio que se educó dentro de las selvas colombianas. Cali: Editorial Universidad del Cauca y Facultad de Humanidades de la Universidad del Valle, 2004, pp. 139-249.

Martha Elena Corrales Carvaja/*

\section{Sobre el autor y estos pensamientos}

Manuel Quintín Lame, "el indiecito que escribe estos pensamientos" (2004:219), nació, según su propio testimonio, el 31 de octubre de 1883 en el resguardo de Polindara, actual resguardo del municipio de Totoró, departamento del Cauca, y murió el 7 de octubre de 1967 en Ortega, Tolima. Con respecto a su nacimiento hay otras versiones: el historiador y amigo de Lame, Juan Friede, dice que nació en el año de 1887 en la hacienda de "Calderetas" en la región de Silvia (1987:10) y Joanne Rappaport afirma que nació en 1883 en la hacienda de "San Isidro" (2004:55).

Manuel Quintín Lame fue hijo de terrajeros paeces en diferentes haciendas de los grandes terratenientes del Cauca que, como su padre, trabajó la tierra de los demás sin recibir casi nada a cambio. No fue a la escuela, pero conoció de cerca y en carne propia los sufrimientos y las explotaciones de los indios. Por eso, cuando a los 18 años (estando en el ejército colombiano, peleando por un país que no lo reconocía

* Profesora de la licenciatura en Etnoeducación de la Universidad del Cauca. Estudiante Doctorado en Educación, Línea Estudios Interculturales, Universidad de Antioquia. E-mail: mcorrales@unicauca.edu.co y corralesmarta@hotmail.com 
plenamente como uno de sus ciudadanos), aprendió a leer y a escribir el español, decidió utilizar este medio de comunicación para denunciar a los terratenientes y al Estado que los subyugaba, y para luchar por la reivindicación de los derechos de los indígenas. Es así como fue el primer indígena colombiano en señalar públicamente la necesidad de la lectura y la escritura del español como una herramienta para enfrentar con la ley a los invasores blancos.

Como él mismo lo expresó: "El presente libro servirá de horizonte en medio de la oscuridad para las generaciones indígenas que duermen en esos inmensos campos que tiene la Naturaleza Divina" (2004:143). Porque "(...) si la pluma del doctor Guillermo Valencia sirve para escribir Anarcos, la pluma del indio Manuel Quintín Lame servirá para defender a Colombia" (2004:153). Este indio letrado asumió el papel histórico de escribir para sus hermanos, los indígenas paeces, convencido de aportar a su liberación y mantenimiento cultural por medio de su organización y lucha social y política: “ (...) por medio de mi fe que dejo escrita en este libro se levantará un puñado de hombres indígenas el día de mañana y tomarán los pupitres, las tribunas, los estrados, las sesiones jurídicas (...)" (2004:191).

Por lo anterior, actualmente Manuel Quintín Lame es considerado por los indígenas nasa como uno de sus ideólogos y líderes políticos del siglo XX. En este texto-que no escribió con su puño y letra, pero que sí concibió y redactó en sus pensamientos y palabras como un libro-, un legado para todos los indígenas de Colombia.

"El libro Los pensamientos del indio que se educó dentro de las selvas colombianas fue dictado por Lame a Florentino Moreno, indio inteligente, de letra clara y elegante"1. Según el propio Lame, esta obra la terminó el 29 de diciembre de 1939; sin embargo, apenas salió a la luz pública, en modo impreso, en 1971, a cargo de la Rosca de Investigación y Acción Social de Bogotá. Luego, en 1987, a los veinte años de la muerte de Quintín Lame, la Organización Nacional Indígena de Colombia, ONIC, publicó una versión de estos pensamientos preparada por Juan Friede. Ahora estos pensamientos vuelven a ser publicados por la Universidad del Cauca y la Facultad de Humanidades de la Universidad del Valle a cargo del antropólogo Cristóbal Gnecco, en una edición que reúne cuatro importantes textos sobre esta obra: "Manuel Quintín Lame: luchador e intelectual indígena del siglo XX", de Gonzalo Castillo; "Manuel Quintín Lame hoy”, de Joanne Rappaport; "Las luchas de Quintín Lame", de Yamilé Nene y Henry Chocué; "Aspectos pedagógicos y filosóficos en Los pensamientos del indio que se educó dentro de las selvas colombianas de Manuel Quintín Lame", de Fernando Romero.

1 Testimonio de Abel Tique, secretario de Quintín Lame en la década de 1930, recogido por Gonzalo Castillo (2004: 35). 


\section{Mi lectura de los pensamientos de Quintín Lame}

Entre los múltiples, variados y todos importantes aspectos históricos, políticos, sociales y educativos de los que trata Manuel Quintín Lame en este libro, íntegramente con la intención de denunciar las explotaciones y atropellos de los blancos, y como una forma de salvar a los indios de "su ignorancia", me centraré en resaltar los siguientes aspectos:

1. Su concepción de la naturaleza en un doble papel: madre y maestra

2. Su concepción y mirada del "otro"

3. Su valor de la escritura del español

Las referencias a estos tres temas los expongo a partir de las propias palabras del autor, en un intento de diálogo con la lectura que he hecho de sus pensamientos.

\section{La naturaleza: madre y maestra de origen divino}

Quintín Lame, como la gran mayoría de los indígenas americanos, acorde con su cosmovisión ancestral, siente, ve y concibe a la naturaleza, y en ella a la tierra, como su madre, como su progenitora. Tal como afirman los actuales indígenas paeces, la naturaleza es su "nasa kiwe", su tierra madre.

Como también es común en muchas sociedades, incluso occidentales y urbanas, el papel femenino de ser madre está íntimamente asociado al de ser maestra, al de quien tiene la obligación y la capacidad de enseñar, de entregar y compartir sus conocimientos. Es así como para Quintín Lame la sabiduría, el conocimiento, la ciencia y la educación están contenidas de manera integral en la naturaleza; están allí para que el ser humano, como él, de manera autodidacta, espontánea, contemplativa y naturalmente las tome.

Aquí se encuentra el pensamiento del hijo de las selvas que lo vieron nacer, se crió y se educó debajo de ellas como se educan las aves para cantar, (...) para hacer uso de la sabiduría que la misma Naturaleza nos ha enseñado, porque ahí en ese bosque solitario se encuentra el Libro de los Amores, el libro de la Filosofía; porque ahí está la verdadera poesía, la verdadera filosofía, la verdadera Literatura (...) (2004:148).

Este pensamiento telúrico del conocimiento, la ciencia y la educación, lo mezcla y lo pone en el mismo nivel, la mayoría de las veces de manera confusa e incoherente, con concepciones teológicas y los principios cristianos católicos tomados y apropiados de los "blancos", con quienes de manera obligada tuvo que interactuar o a quienes tuvo que obedecer. 
Esa Reina llamada la Naturaleza de que tanto me ha indicado la Ontología allá en el bosque donde alcancé a divisar el jardín de la ciencia llamada la Teodicea, la que me indicó cómo se debía interpretar el pensamiento humano y cómo debía defenderme (2004:169).

La sombra Misteriosa de Jehová se convirtió en rayo de luz, (...) haciéndome comprender que ya no existía el salvajismo, la ineptitud, y que ya no era el asno montés, sino el indio aficionado que debía conocer los destinos humanos que encierran el Misterio de la vida del hombre: (...) quien se inspiró en la montaña, se educó en la montaña y aprendió a pensar, para pensar en la montaña (...) (2004:239).

(...) el indiecito no ha gozado o conocido esos principios de conocimientos o educación; pero la naturaleza me educó debajo de sus sombras, de sus calores y sus hielos; ella me mostró ahí debajo de dichas sombras el idilio de la poesía; también me mostró sus tres reinos mineral, animal y vegetal; ella me enseñó a pensar, para pensar, ella me indicó donde estaba mi escritorio en el desierto y que me fue entregado por la soledad (2004:236. El destacado es mío).

Ese concierto de filósofos que tienen esos tres poderosos reinos y que forman un libro, una lógica donde se encuentran todos los teoremas fundamentales de la Ciencia del Mundo material y también de la Ciencia del Mundo Espiritual; ¿dónde se encuentra la cuna de la Sabiduría? Pues la cuna de la Sabiduría está debajo de crueles montañas escondidas (...) ¿Qué cosa es la naturaleza? La naturaleza es el Libro de Dios y la Ciencia de Dios es infinita y la Ciencia del hombre es finita (2004:150-151).

Este conocimiento prodigado por la naturaleza es recibido e interiorizado por Quintín Lame como la mayor obra de Dios y del Espíritu Santo. Este conocimiento es concebido por él como otra manera de mostrar las diferencias entre los indios y los blancos, y de evidenciar la inteligencia de los indios; este conocimiento, esta educación y este aprendizaje los asume como una forma de dejar de ser un indio ignorante, viendo en la educación un proceso de ascenso intelectual, para alcanzar y superar los niveles intelectuales de los blancos.

No es verdad que sólo los hombres que han estudiado quince o veinte años, los que han aprendido a pensar para pensar, son los que tienen vocación (...). Pues yo nací y me crié en el monte, y del monte bajé hoy al valle a escribir la presente obra (2004:144).

(...) todos hablan de los claustros de educación; por esta razón yo también debo hablar como lo hago de los claustros donde me educó la Naturaleza; ese Colegio de mi educación (...) todos estos libros nacen de la 
Teodicea, es decir: es el origen o fuente de donde nacen; que estos libros fueron mi consuelo y mañana serán las virtudes en el Paraíso de las Bienaventuranzas (...) Estos libros de mi estudio (...) pero no están todos, porque son miles y miles de libros los que no han podido hojear aquellos hombres que se chamuscaron los párpados de sus vistas de quince a veinte y treinta años de estudio, etc. (2004:240-244).

(...) esa humanidad que ha pasado y pasó no ha podido comprender lo que está escrito en ese hermoso libro, llamado El libro de Dios. (2004:145. El destacado es mío).

Tomando distancia de este origen divino de la educación y del conocimiento, la mirada holística y un tanto romántica de la naturaleza como un todo perfecto, armónico y lógico, como un ser activo, propositivo e interactivo con los seres humanos, es uno de los fundamentos para su concepción indígena de la educación. Concepto de la naturaleza vigente en las propuestas de una educación propia y contextualizada que actualmente están haciendo las comunidades y organizaciones indígenas.

(...) para Lame y diversas comunidades indígenas, el espacio no es un ente físico, un accidente, pues seres humanos y espacio se compenetran con la experiencia de lo sagrado; por eso el lugar de la variedad, de lo inusitado (Romero, 2004:121).

La relación entre el indio y la naturaleza es una relación simétrica; no existen seres superiores ni inferiores, pues todos comparten un mismo destino, un mismo espacio y un mismo designio (Romero, 2004:125).

Como lo afirma Graciela Bolaños (en Nene y Chocué, 2004:103-104), Quintín Lame sembró las

raíces de una pedagogía indígena (...) argumentó una educación en estrecha relación con la naturaleza, encontrando en la contemplación de su ordenamiento muchas enseñanzas (...) Lame planteó que la pertinencia de la educación depende de la relación que se establezca con la naturaleza, de la calidad de las enseñanzas que se obtengan de ella, de la disposición para observarla, conocerla y escuchar sus consejos (...) El conocimiento natural no es acumulativo; es permanente y dinámico.

Y tal como también lo plantea Fernando Romero, Quintín Lame

(...) quiso afirmar la oposición entre la educación indígena y la del blanco, entre la educación libresca y su educación basada en la experiencia, entre la naturaleza y la sociedad blanca; es decir, su objetivo fue establecer la dualidad en la cual se configura la condición indígena y los referentes de una educación diferenciada (2004:120). 
(...) la manera como planteó los referentes educativos y retomó la información que circulaba en esta época le permitió desarrollar, por primera vez en Colombia, una propuesta renovadora y pionera de educación indígena, una perspectiva neoindigenista de formación cuyo eje es la naturaleza y la experiencia, en oposición a una concepción libresca, de carácter religioso, propio de las escuelas públicas de comienzos del siglo $\mathrm{XX}$ (2004:133).

\section{Concepción y mirada del "otro": señalamiento de las diferencias entre los indios y los blancos}

Retomando nuevamente a Romero (2004:114), otro planteamiento constante en estos pensamientos de Manuel Quintín Lame fue mostrar cómo piensa el pensar para definir un paradigma desde el cual pensar la diferencia, es decir, aquello que caracteriza al indígena y, desde allí, derivar una perspectiva educativa.

Esta mirada del otro, en este caso del "blanco" de origen europeo, es dicotómica y excluyente, planteada muy en "blanco y negro", en víctimas y victimarios, en buenos y malos. Esta concepción no es gratuita, pues como indio así lo vivió; con el blanco no experimentó relaciones de interacción e intercambio, sino de choque, dominación y explotación.

(...) los extranjeros no son hijos de la naturaleza sino hijos de piedras" (2004:187).

(...) el corazón del blanco es la mansión de la envidia y persecusión (sic) contra el pobre indígena ingnorante (2004:188).

El indio por confiado le ha entregado todo al blanco sin saber la supremacía de su inteligencia (2004: 191).

La pobreza del blanco es triste, penosa, vergonzosa, motivo a la envidia y mala fe de éste con el pobre indígena, por nuestra ignorancia, sencillez y analfabetismo (2004: 207).

Como ya se señaló en el aparte anterior, otra dimensión en la que Lame señala las hondas diferencias entre los indios y los blancos es en la concepción de la naturaleza. Contraria a la concepción que tenían los "blancos" de esa época, que también sigue vigente en el pensamiento occidental, de la naturaleza como un ser pasivo, distante y distinto del ser humano, que sólo requería ser estudiada, conocida, controlada y aprovechada, para los indígenas el ser humano hace parte integral de la 
naturaleza. Una naturaleza que al contemplarla, sentirla y vivirla se aprende a interpretar, y es la que enseña sus propios secretos, y al conocer sus lógicas se pueden conocer las lógicas de los seres humanos y de las sociedades. Para Quintín Lame y para los indígenas de hoy, los que buscan mantener su pensamiento tradicional, hay relaciones de correspondencia y equilibrio entre las dinámicas internas y propias de la naturaleza (de la que hace parte el ser humano) con las dinámicas sociales y culturales de los seres humanos.

Esta concepción de la naturaleza, fundamento para sentirla como madre y maestra educadora, marca otra diferencia entre los "blancos" y los indios: su forma de aprender, de conocer, de educarse.

Pues esa naturaleza que tiene sus armoniosos cantos enseñados los que vienen educados por generaciones y no por maestros como ha aprendido a leer y escribir el blanco, enemigo del indio (2004:193-194).

(...) los hombres, los niños y los jóvenes que se pasean con varios libros estudiándolos donde está escrita la Ciencia, pero esto es para aprender a decir lo que saben, y saber lo que van a decir; pero el hijo de las selvas dice es lo que vio y le consta, porque con un yo lo vi es la razón y la justicia conmutativa, distributiva y legal ante Dios y los hombres.

Los jóvenes no indígenas con un interés personal aprenden lo que está escrito en dichos libros, sea o no sea la verdad (...) (2004:215- 216).

Sin embargo, llama la atención que marcando y señalando reiteradamente las diferencias entre cómo aprenden los unos y los otros, denigrando del conocimiento y del modo de conocer de los blancos, también hace notar que sí ha leído sus textos, que él también ha accedido al saber producido por los "blancos", pues también de manera reiterada cita a autores, conceptos, planteamientos y textos de "ellos", como apartes y referencias de la literatura griega, del Quijote, de la religión, de la Biblia, de las leyes. Esto, como otra forma de mostrar las capacidades de los "indios" para hablar el mismo idioma y utilizar las mismas armas de sus enemigos, los blancos.

\section{Valor de la escritura del español: denuncia, educación y liberación para los indígenas}

Como ya se mencionó, el principal objetivo de Lame al "escribir con su oralidad y palabras dictadas" este libro, fue denunciar los atropellos de los que eran víctimas los indios por parte de los blancos. Es así como encontramos una primera valoración de la escritura: la denuncia y defensa contra los "blancos invasores": 
Los misterios que tiene la Naturaleza humana no lo ha revelado a los hombres como los reveló la Naturaleza Divina, de donde he podido yo transformar mi salvajismo en aficionado, y dar a luz esta Obra de pensamientos, no con lenguaje castizo, ni caligrafía de pluma, porque la civilización española al conocer mi obra, la que llegó el 12 de octubre, hará sonar sus labios Cras, Cras, Cras; pero yo digo y sostengo, como dijo el Gobernador Romano, lo que está escrito, está escrito (2004:245).

Tal como lo señala Rappaport (2004:66):

(...) la obra delinea tres grandes periodos en la historia de los indígenas colombianos: el pasado precolombino, un período de opresión europea que comenzaría en 1492 y su futura salvación, a la que daría inicio la finalización del libro en 1939 (el destacado es mío).

Quintín Lame siempre vio con preocupación el analfabetismo de los indios, pues advertía en esta supuesta ignorancia las condiciones y las causas de su esclavitud y explotación por parte de los "blancos". En tal sentido

(...) Quintín consideraba que su misión era educar a las comunidades, para que, conscientes de su situación, no dejaran engañarse de sus enemigos (ONIC, 1987:6).

Una de las bases para la educación, organización y liberación de los indios era conocer las leyes de los "blancos", tanto las que servían a sus intereses, como las pocas que velaban por el "bienestar de los indios". Fue así como

(...) Quintín Lame encontró apoyo legal en la Ley 89 de 1890, e hizo de ella su principal bandera de lucha. La enseñanza de esta Ley a los indígenas se convirtió en el eje de su campaña (Castillo, 2004:28).

De otra parte,

Lame aprovechó la literatura de su época, apropiándola para construir un argumento político sobre los derechos del indígena colombiano, un argumento que no compartió con los autores que leía; es decir, se valió de metodologías de apropiación que hoy día se llamarían interculturalidad, la reinterpretación de ideas externas encaminadas a la construcción de una propuesta política (Rappaport, 2004:70).

\section{Algunas ambigüedades en estos pensamientos de Lame}

En este texto oral-escrito de Quintín Lame, si bien permanentemente habla de los valores de los "indios", de su inteligencia y la importancia de recuperar sus tierras, 
llama la atención una cierta ambigüedad en el conocimiento y la valoración de su cultura, especialmente de su lengua. Se puede ver por un lado el orgullo de ser indígena, pero la necesidad de cambiar su condición para alcanzar un mejor estatus en la sociedad: querer seguir siendo indio, pero teniendo que dejar de ser lo que es.

Pues la imagen de mi pensamiento se transformó por medio de un sueño misterioso debajo de las selvas de la ignorancia y de mi analfabetismo cuando saludaba diciendo auchingá; y no era auchingá sino buenos días, cuando me despedía de mi abuelo cuscachi, y no era cuscachi, sino hasta mañana: pues se transformó mi lenguaje como se transformaron mis pensamientos los que hoy están transformados en ideas, no por lenguaje castizo ni estudiarlo en ninguna escuela primaria ni tampoco en ningún colegio donde han estudiado tantos años mis enemigos no indígenas (2004:226).

Otra ambigüedad señalada por Rappaport es la sobrevaloración que Lame hace de la lectura por encima de la oralidad tradicional de su comunidad, manifiesta en cierto desconocimiento de costumbres, mitos y valores culturales que se transmitían por esta vía. Esto se podría explicar en dos hechos: primero, que Quintín Lame se centró en luchar por la recuperación de las tierras de los indígenas, más desde una perspectiva política que cultural; segundo, en el hecho de que tuvo que salir de su comunidad de origen, huyendo de los terratenientes, por lo cual la mayor parte de su vida la vivió entre la cárcel y el Tolima.

A pesar de su énfasis en la cultura indígena, las referencias culturales son genéricas y no parten de la cultura nasa, es decir, surgen de investigaciones bibliográficas hechas por el autor y no por su propio conocimiento cultural (...) Parece que incluso la referencia que hace de Juan Tama de la Estrella, otro gran líder espiritual y político de los nasa, fuera producto de "sus investigaciones de archivo" porque la paleografía del siglo XVIII hace que un lector moderno se confunda entre la T y la F, como hace Lame aquí, sugiriendo que su conocimiento de Juan Tama proviene de un documento escrito y no de la tradición oral (Rappaport, 2004:68).

A pesar de estas dos ambigüedades, estos pensamientos de Manuel Quintín Lame siguen vigentes entre los paeces, y siguen siendo un referente político, educativo y cultural fundamental para sus procesos organizativos y reivindicativos:

(...) más de tres décadas después de su publicación y en el contexto del movimiento indígena que maduró en los años posteriores a la publicación de 1971, el libro de Quintín Lame es una herramienta indispensable para la educación política de las comunidades indígenas (Rappaport, 2004:54). 


\section{Referencias bibliográficas}

Castillo, Gonzalo. "Manuel Quintín Lame: luchador e intelectual indígena del siglo XX", en Cristóbal Gnecco (editor), Los pensamientos del indio que se educó dentro de las selvas colombianas. Cali: Editorial Universidad del Cauca, 2004, pp. 13-49.

Lame, Manuel Quintín. "Los pensamientos del indio que se educó dentro de las selvas colombianas", en Cristóbal Gnecco (editor), Los pensamientos del indio que se educó dentro de las selvas colombianas. Cali: Editorial Universidad del Cauca, 2004, pp. 139249.

Los pensamientos del indio que se educó dentro de las selvas colombianas (versión de Juan Friede). Organización Nacional Indígena de Colombia, 1987. Sin más datos.

Nene, Yamilé y Chocué, Henry. "Las luchas de Quintín Lame", en Cristóbal Gnecco (editor), Los pensamientos del indio que se educó dentro de las selvas colombianas. Cali: Editorial Universidad del Cauca, 2004, pp. 103-110.

Rappaport, Joanne. "Manuel Quintín Lame hoy", en Cristóbal Gnecco (editor), Los pensamientos del indio que se educó dentro de las selvas colombianas. Cali: Editorial Universidad del Cauca, 2004, pp. 51-101.

Romero, Fernando. "Aspectos pedagógicos y filosóficos en Los pensamientos del indio que se educó dentro de las selvas colombianas de Manuel Quintín Lame", en Cristóbal Gnecco (editor), Los pensamientos del indio que se educó dentro de las selvas colombianas. Cali: Editorial Universidad del Cauca, 2004, pp. 111-138. 